\title{
MANEJO DE NABO COM OS HERBICIDAS SAFLUFENACIL E BENTAZONA NA CULTURA DO TRIGO
}

\author{
Maicon Fernando Schmitz ${ }^{1}$ \\ Cristiano Piasecki ${ }^{2}$ \\ Marcos Belinazzo Tomazetti ${ }^{3}$ \\ Jonas Henckes ${ }^{4}$ \\ Jessica Garcia ${ }^{5}$ \\ Daniela Tessaro ${ }^{6}$ \\ Gustavo Sessa Fialho ${ }^{7}$
}

Resumo: O nabo (Raphanus raphanistrum) é uma planta daninha que interfere na produtividade final do trigo. O uso repetido de herbicidas inibidores da enzima ALS favoreceram a seleção de biótipos resistentes, tornando necessário o uso de herbicidas alternativos. O objetivo do trabalho foi avaliar o controle de nabo e seletividade ao trigo sob diferentes doses de saflufenacil e bentazona, e outros herbicidas de uso comum nesta cultura. O estudo foi realizado em casa de vegetação em delineamento inteiramente casualizado com quatro repetições. Os tratamentos de saflufenacil (0; 8,5; 17; 35 e $70 \mathrm{~g}$ ha-1), bentazona (0; 180; 360; 720 e $1440 \mathrm{~g}$ ha-1), metsulfurom metílico (3,6 g ha-1) e 2,4-D (670 g e.a. ha-1), além da testemunha capinada. As variáveis analisadas foram controle de nabo e fitotoxicidade ao trigo aos 8 e $14 D A A$. Os resultados evidenciaram que o controle de nabo foi superior a 90\% aos 14 DAA para doses superiores a 17 e $360 \mathrm{~g}$ ha-1 de saflufenacil e bentazona, respectivamente. Ao comparar com os tratamentos adicionais, observouse que ambos os herbicidas podem substituir o metsulfurom-metilico e o 2,4-D para controle de nabo. Palavras-chave: Triticum aestivum; Seletividade; Raphanus raphanistrum; Controle; Planta daninha.

\footnotetext{
1 Mestrado em Fitossanidade/UFPel, Brasil. E-mail: maicon_schmitz@hotmail.com.

2 Doutorado em Fitossanidade/UFPel, Brasil. E-mail: c_piasecki@hotmail.com.

${ }^{3}$ Mestrado em Fitossanidade/UFPel, Brasil. E-mail: marcosbelinazzotomazetti@gmail.com.

${ }^{4}$ Mestrado em Fitossanidade/UFPel, Brasil. E-mail: jhenckes@hotmail.com.

${ }^{5}$ Mestrado em Fitossanidade/UFPel, Brasil. E-mail: jejesvp@hotmail.com.

${ }^{6}$ Mestrado em Fitossanidade/UFPel, Brasil. E-mail: dani.tes@hotmail.com.

7 Departamento de Matemática e Estatística/UFPel, Brasil. E-mail: gsfialho@hotmail.com.
} 